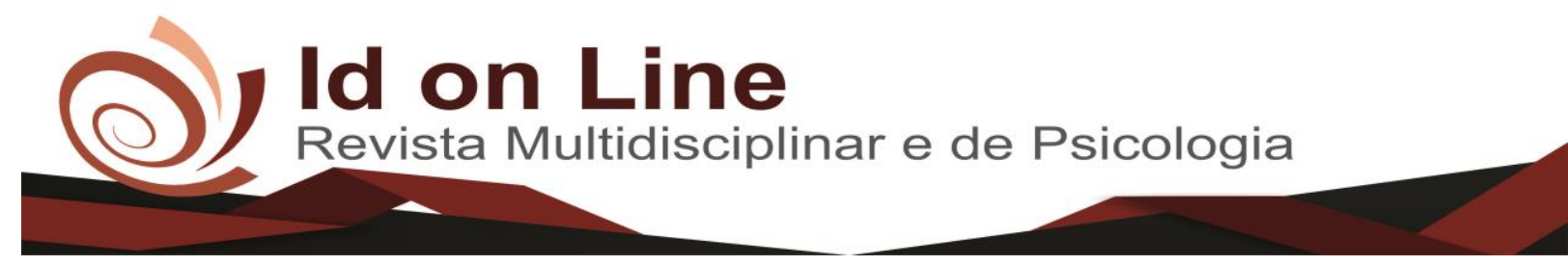

Editorial

\title{
Por um novo modelo de saúde no Brasil
}

Manuela Sobral Bentes de Melo ${ }^{1}$

Resumo: A saúde pública no Brasil tem passado por diversas mudanças ao longo dos anos, mas que não foram efetivas em sanar questões importantes sobre uma gestão defíciente. É de grande importância que os gestores indicados para tais funções, estejam qualificados para o enfrentamento dos graves problemas que assolam o sistema atualmente. O objetivo do editorial é discutir e comentar uma visão realista desta problemática, de forma a tentar alertar a comunidade científica sobre tais desafios. Diante disso, é urgente que os gestores públicos se apropriem da realidade e que sejam mais ágeis em implementar ações, que sejam capazes de mudar o atual estado da saúde da população.

Palavras-chave: Saúde pública. Gestão da Saúde. Desafios.

\section{For a new health model in Brazil}

\begin{abstract}
Public health in Brazil has undergone several changes over the years but has not been effective in addressing important issues about poor management. It is of great importance that the managers indicated for such functions, are qualified to face the serious problems that plague the system today. The objective of the editorial is to discuss and comment on a realistic view of this problem, in order to try to alert the scientific community about such challenges. Given this, it is urgent that public managers take ownership of reality and are more agile in implementing actions that are capable of changing the current health status of the population.
\end{abstract}

Keywords: Public health. Health Management. Challenges.

A saúde tem se mostrado um dos temas preocupantes para a população. Tal sentimento não acontece por acaso. A mídia tem mostrado inúmeras situações indesejáveis, em termos de saúde, acompanhadas de tragédias protagonizadas por crianças e adultos por todo o país, desde as longas filas de espera, até os equipamentos obsoletos ou fora de uso por descaso na manutenção.

As desculpas são normalmente a escassez de recursos. Pouco se fala da má gestão e negligência de muitos gestores públicos.

\footnotetext{
${ }^{1}$ Médica pelo Centro Universitário Christus, UNICHRISTUS, Brasil. Contato: manuelasbmelo@gmail.com.
} 
$\mathrm{O}$ avanço das pesquisas tem implicado em maiores exigências nos procedimentos, também mais sofisticados, de forma a tornarem mais precisos os diagnósticos. O progresso impõe seus custos.

Com a redemocratização do país, muitas foram as conquistas sociais, dentre elas a implantação do Sistema Único de Saúde (SUS). Este foi um modelo idealizado à partir da $8^{\text {a }}$ Conferência de Saúde em 1986, e que ganhou força e formato quase definitivo com a Constituição de 1988, segundo a qual, em seu artigo 196, a saúde seria um "direito de todos e dever do Estado, garantido mediante políticas sociais e econômicas que visem à redução do risco de doença e de outros agravos e ao acesso universal e igualitário às ações e serviços para sua promoção, proteção e recuperação" (BRASIL, 1988).

A cada ano que se passa, parece aumentar a distância entre as determinações constitucionais e a realidade. Enormes filas, corredores abarrotados de macas, pacientes medicados em locais nem sempre apropriados, escassez de medicamentos, de profissionais e de equipamentos, além de infraestrutura em desacordo com as normas legais. As pessoas que buscam atendimento no serviço público, tem retornado para seus lares sem a ajuda necessária. Há casos inclusive de perecerem e não conseguirem voltar. Portanto, para uma boa parcela da população, a busca por socorro em unidades públicas governamentais parece uma ida ao encontro do desconhecido.

O cidadão, ante o descaso, tende a usar o instrumento jurídico ao seu favor, como recurso extremo para que o Estado venha a cumprir com o seu dever. Só entre 2009 e 2014, cresceu $491 \%$ o número de ações judiciais, efetivamente um total de 62.020 processos. A maior parte destes foram relacionados ao acesso a medicamentos. A União precisou de um desembolso de mais de R \$ 843 milhões (MINISTÉRIO DA SAÚDE, 2016).

Atualmente, a situação tem se agravado ante a crise econômica, uma das mais difíceis desde os anos 1990. Com a alta inflação, o desemprego crescente, as taxas de juros elevadas, a qualidade de vida fica bastante comprometida e, impulsionam uma migração do brasileiro que tem plano de saúde, para os serviços rede pública, a custo zero, mas que se mostra incapacitado para atender a essa crescente demanda.

O Ministério da Saúde, contou em 2016, com um orçamento de R \$ 109,414 bilhões e, mesmo assim, o valor não foi suficiente para atendimento das urgências sociais deste setor. A gestão das políticas de saúde não parecem apresentar os efeitos desejados. São muitas as dificuldades em termos de gerenciamento profissional, somando-se a tudo isso, a grande 
corrupção. Já houve em épocas anteriores, ações mais efetivas da Polícia Federal e da Controladoria-Geral da União, onde diversos mandatos de prisão e apreensão foram executados, a maioria por desvios de verbas e recursos do Fundo Nacional de Saúde por governantes estaduais despreparados ou mal intencionados.

É uma pena que muitas das epidemias no país, aconteçam por descaso, má gestão ou corrupção. O setor saúde brasileiro sofre da contaminação da ineficiência na prestação de serviços públicos, que são, por sua vez, incompatíveis com a grande carga tributária que tem sido imposta aos cidadãos. É difícil, quando não, revoltante presenciar a brasileiros que perdem a sua saúde e, em alguns casos a própria vida, em decorrência dos transtornos impostos à saúde pública. Os governos não falam, ao contrário, usam a mídia para transparecer uma outra realidade. Enquanto isso, nos bastidores, funções gerenciais são moedas de troca por algum apoio recebido em época eleitoral. Pondo em risco a saúde e a vida das pessoas.

Portanto, é urgente uma revisão no atual sistema de saúde, ora implantado no país, para que possamos alcançar níveis mais eficientes de atendimento em saúde para a população.

A hospitalização, que deveria ser o último recurso, tem sido a porta de entrada para os muitos usuários em busca de diagnósticos. Mais seriedade, evitando-se as negociatas políticas, favorecedoras dos desvios de recursos que corroem as estruturas sociais capazes de manter as condições mínimas de saúde da população. Enfim, chegou o momento de exigir um tratamento mais digno à saúde e aos profissionais de saúde, indiretamente a todo o cidadão brasileiro.

\section{Referências}

BRASIL. Constituição (1988). Constituição da República Federal do Brasil. Brasília, DF: Senado Federal, 1988.

BRASIL. MINISTÉRIO DA SAÚDE. Dados e indicadores da saúde de 2016. Disponível em http://portalms.saude.gov.br. Acesso em 12.12.2017.

\section{Como citar este artigo (Formato ABNT):}

MELO, Manuela Sobral B. de. Por um novo modelo de saúde no Brasil. Id on Line Revista ultidisciplinar e de Psicologia, 2017, vol.12, n.39, p.505-507. ISSN: 1981-1179.

Recebido: 03.01.2017

Aceito: 06.01 .2018 